\title{
Trajectories of anxiety and depression in liver transplant candidates during the waiting-list period
}

Coby Annema ${ }^{\prime} *$ (D), Petrie F. Roodbol', Edwin R. Van den Heuvel ${ }^{2}$, Herold J. Metselaar ${ }^{3}$, Bart Van Hoek ${ }^{4}$, Robert J. Porte ${ }^{5}$ and Adelita V. Ranchor ${ }^{6}$

'Department of Nursing Research, University Medical Center Groningen, University of Groningen, the Netherlands

${ }^{2}$ Department of Mathematics and Computer Science, Eindhoven University of Technology, the Netherlands

${ }^{3}$ Department of Gastroenterology and Hepatology, Erasmus Medical Center, Rotterdam, the Netherlands

${ }^{4}$ Department of Gastroenterology and Hepatology, Leiden University Medical Center, the Netherlands

${ }^{5}$ Department of Surgery, Section of Hepato-Pancreatic-Biliary Surgery and Liver Transplantation, University Medical Center Groningen, University of Groningen, the Netherlands

${ }^{6}$ Department of Health Psychology, University Medical Center Groningen, University of Groningen, the Netherlands

Objectives. To explore whether distinct trajectories of anxiety and depression exist among liver transplant candidates, and to gain insight into demographic, clinical, and individual characteristics related with these trajectories.

Design. A multicentre, prospective cohort study among 216 liver transplant candidates. Respondents filled out a questionnaire at study entrance and subsequently every 6 months until transplantation or removal from the waiting list.

Methods. Anxiety (STAI6), depression (CES-D), demographic, and individual variables were assessed by questionnaire. Clinical variables were retrieved by medical record review. The SAS PROC TRAJ procedure was used to identify distinct trajectories. Univariate and multiple ordinal logistic regression analyses were used to explore related variables.

Results. Regarding anxiety, three stable trajectories were identified as follows: below clinical level (5I\%), slightly above clinical level (34\%), and high above clinical level (I5\%). Regarding depression, four stable trajectories were identified as follows: below clinical level $(23 \%)$, slightly below clinical level (34\%), slightly above clinical level (28\%), and high above clinical level (6\%). For anxiety as well as for depression, experiencing more liver disease symptoms, a lower level of personal control, making more use of emotional coping, and making less use of task-oriented coping increased the likelihood of membership in those trajectories with higher symptom levels.

*Correspondence should be addressed to Coby Annema, Department of Nursing Research, PO Box 30.00 I (FCI4), 9700 RB Groningen, The Netherlands (email: j.h.annema@umcg.nl). 
Conclusion. Distinct, but stable, trajectories of anxiety and depression were present in liver transplant candidates. The trajectories with symptom levels above clinical relevant levels for anxiety or depression comprised, respectively, $49 \%$ and $34 \%$ of the respondents. Therefore, psychological screening and subsequently providing appropriate interventions are warranted early in the transplant process.

\section{Statement of contribution}

What is already known on this subject

- For transplant candidates, the waiting-list period is a period of uncertainty and unpredictability.

- Psychological problems, such as anxiety and depression, are common among liver transplant candidates.

- Several demographic, clinical, and individual characteristics are associated with anxiety and depression, but these results remain inconclusive.

\section{What does this study add}

- Distinct trajectories of symptoms of anxiety and depression are present among liver transplant candidates.

- Given the stability of the trajectories over time, the symptom level at baseline is indicative of the symptom level during the waiting-list period.

- Experiencing more liver disease symptoms, low mastery, more use of emotional coping, and less use of task-oriented coping are associated with trajectories of high symptom levels.

In the Eurotransplant region, over 2,000 patients with end-stage liver disease are waiting for a liver transplant, while about 1,600 patients per year receive a liver transplant (Eurotransplant International Foundation, 2015). More specifically, in the Netherlands, about 200 patients are placed on the waiting list for a liver transplant per year, while approximately 145 patients receive a liver transplant (Dutch Transplantation Society, 2015). Due to the gap between supply and demand for organ donors, transplant candidates may have to wait for a donor offer for a prolonged period of time. Each year approximately $15 \%$ of transplant candidates die while on the organ transplant waiting list (Dutch Transplantation Society, 2015).

Waiting for a new organ puts much stress on patients. Not only are they confronted with deterioration in their physical health but they also have to deal with uncertainty - will the transplant come in time - and unpredictability - when will the transplant take place (Haugh \& Salyer, 2007; Martin, Stone, Scott, \& Brashers, 2010; Moran, Scott, \& Darbyshire, 2011; Toimamueang et al., 2003). Although the prospect of a transplantation offers new hope for the future, transplant candidates often feel that their life is on hold (Moran et al., 2011; Rosenberger, Dew, DiMartini, DeVito Dabbs, \& Yusen, 2012).

Given the stressors encountered by transplant candidates, it is not surprising that psychological problems, such as anxiety and depression, are common during the waiting-list period. Among liver transplant candidates, prevalence rates of $14-52 \%$ regarding anxiety (Gutteling, de Man, Busschbach, \& Darlington, 2007; Lopez-Navas et al., 2011; Miller et al., 2013; Russell, Feurer, Wisawatapnimit, Salomon, \& Pinson, 2008; Stewart, Hart, Gibson, \& Fisher, 2014) and of 17-60\% regarding depression (Guimaro, Lacerda, Karam, Ferraz-Neto, \& Andreoli, 2008; Gutteling et al., 2007; Lopez-Navas et al., 2011; Miller et al., 2013; Russell et al., 2008; Stewart et al., 2014) have been described. These prevalence rates vary widely because of differences in screening instruments and cut-off scores used.

Psychological problems before transplantation have been associated with poor psychological health after transplantation (Caccamo et al., 2001; Miller et al., 2013; Rogal, Landsittel, Surman, Chung, \& Rutherford, 2011), which in turn has been associated 
with poorer outcomes after transplantation regarding adherence (Chiu, Chen, \& Cheng, 2009; Errichiello, Picozzi, \& de Notaris, 2014), quality of life (Errichiello et al., 2014; Kugler et al., 2013; Miller et al., 2013), and mortality (Corruble et al., 2011; Rogal, Dew, Fontes, \& DiMartini, 2013). Therefore, effective treatment of symptoms of anxiety and depression during the waiting-list period may contribute to an optimal preparation for transplantation and better outcomes after transplantation.

So far, little is known about the evolution of symptoms of anxiety and depression during the waiting-list period, because most studies describing prevalence rates of anxiety and depression have a cross-sectional design, and data are often assessed before or shortly after placement on the waiting list. Regarding liver transplant candidates, two studies have described the course of symptoms of depression and anxiety as remaining stable during the first 6 months after placement on the waiting list (Goetzmann et al., 2006; Malik et al., 2014). Three studies among lung, heart, and kidney transplant candidates revealed an increase in symptoms of anxiety and depression over time during the waiting-list period (Corruble et al., 2010; Vermeulen, Bosma, van der Bij, Koeter, \& Ten Vergert, 2005; Zipfel et al., 1998). However, these studies examined the course of symptoms of anxiety and depression on a group level. Distinct trajectories, representing clusters of individual developmental courses for symptoms of anxiety and depression during the waiting-list period, have not been examined yet. Thus, we do not know whether transplant candidates become increasingly anxious over time, or whether transplant candidates who are already depressed remain depressed.

Most studies describing on trajectories of anxiety and depression in other chronic illness patient groups (Ng, Tan, Mooppil, Newman, \& Griva, 2015; Yohannes et al., 2016) or in cancer patients during medical treatment (Henselmans et al., 2010; Lam et al., 2013) distinguished four distinct patterns: chronic low symptom levels, chronic high symptom levels, increasing symptom levels, and decreasing symptom levels. In most studies, the majority of respondents (50-68\%) showed chronic low symptoms levels, whereas a minority (9-24\%) showed chronic high symptom levels, and 20-30\% showed fluctuating symptom levels. Based on these results, it might be hypothesized that the majority of the transplant candidates will show low symptom levels of anxiety and depression over time and that only a minority will show high symptom levels over time. Besides this, a significant subset of transplant recipients may show an increase in symptom level over time due to the deterioration in health status and an increase in feelings of uncertainty.

In addition, insight into the demographic, clinical, and individual characteristics that distinguish the distinct trajectories of symptoms of anxiety and depression can provide health care workers with valuable insights for interventions aimed at reducing distress during the waiting-list period. In the literature, several variables have been related with higher levels of anxiety and/or depression in transplant candidates. These include demographic characteristics, such as age, sex, marital status, and employment status (Corruble et al., 2011; Lopez-Navas et al., 2011; Sainz-Barriga et al., 2005; Santos et al., 2010); clinical characteristics, such as the Model for End-stage Liver Disease (MELD) score; time on the waiting list; and perceived health status (Gutteling et al., 2007; MartinRodriguez, Perez-San-Gregorio, Dominguez-Cabello, Fernandez-Jimenez, \& Perez Bernal, 2012; Rogal et al., 2011) and individual characteristics, such as coping style, personal control, social support, and self-efficacy (Dew et al., 1994; Gutteling et al., 2007; LopezNavas et al., 2011). However, other studies have shown contradictory results regarding these factors (Martins, Sankarankutty, Silva, \& Gorayeb, 2006; Ye et al., 2013). Although these variables are related with higher levels of anxiety and depression measured on a 
group level, we have to rely on these studies to identify possible predictors for distinct trajectories, because studies on distinct trajectories are lacking.

Therefore, the aim of this study was to explore whether distinct trajectories of anxiety and depression are present in liver transplant candidates, how these trajectories evolve over time, and to identify which demographic, clinical, and individual characteristics are related with these trajectories.

\section{Materials and methods}

This study was part of a prospective cohort study on psychological aspects of liver transplantation among transplant patients of three liver transplant centres in the Netherlands. All transplant candidates on the waiting list between October 2009 and April 2013 were eligible to participate if they were 18 years or older, and received pretransplant care in one of the transplant centres. Exclusion criteria were as follows: not being able to fill out a questionnaire due to physical, mental, or cognitive functioning, or a language barrier.

Informed consent was obtained from all the individual participants included in the study. After written informed consent, respondents received a baseline questionnaire (T0), which they were asked to fill out within 2 weeks. A reminder was sent after 2 weeks, if necessary. The measurement of symptoms of anxiety and depression was repeated every 6 months (T1-T7) after inclusion in the study until either transplantation, removal from the waiting list, death during the waiting-list period, or the end of the study in October 2013.

The institutional review board of the transplant centre that initiated the study approved the study, and a positive recommendation of local feasibility was obtained from the other transplant centres (METc2009.190).

\section{Measurements}

\section{Outcome variables}

The outcome variables of anxiety and depression were included in the questionnaire at all measurement points.

Symptoms of anxiety were measured using the short form of the State-Trait Anxiety Inventory (STAI-6) (Marteau \& Bekker, 1992). The STAI-6 consists of six items rated on a 4point intensity scale (from $1=$ not at all to $4=$ very much), resulting in a total sum score between 6 and 24. Higher scores indicate more symptoms of anxiety. Based on a transformation of the original 20-item scale cut-off of $\geq 40$ for the general population (Spielberger, Gorsuch, Lushene, Vagg, \& Jacobs, 1983), a cut-off score of $\geq 12$ was used to identify clinically relevant cases. The convergent validity of the STAI-6, with the full form of the STAI, showed a correlation of .95 (Van der Bij, De Weerd, Cikot, Steegers, \& Braspenning, 2003). Cronbach's $\alpha$ of the STAI- 6 in this study varied from .75 to .88 at the different measurement points.

Symptoms of depression were assessed using the Dutch version of the Center for Epidemiological Studies Depression scale (CES-D) (Bouma, Ranchor, Sanderman, \& Van Sonderen, 1995). The CES-D consists of 20 items, scored on a 4-point self-report scale (from $0=$ seldom or never to $4=$ most of the time/always). Higher scores indicate more symptoms of depression. A cut-off score of $\geq 16$ was used to identify clinically relevant 
cases (Radloff, 1977). Cronbach's $\alpha$ of the CES-D in this study varied from .79 to .94 at the different measurement points.

\section{Predictor variables}

All predictor variables were measured once at the baseline measurement (T0).

Demographic characteristics regarding age, sex, marital status, educational level, and employment status were retrieved by self-report.

Clinical characteristics regarding primary liver disease, presence of hepatocellular carcinoma (HCC), time since diagnosis, time on waiting list, MELD score at time of listing, number of comorbidities, and the severity of liver disease symptoms were examined. Most of the variables were retrieved by medical record review. To measure comorbidity and liver disease symptoms, two research instruments were included in the questionnaire:

1. To measure comorbidities, a checklist of twenty common medical problems adapted from the health survey of the Dutch central statistics office, Statistics Netherlands, was used (www.cbs.nl; accessed 01/15/2015). This checklist included common medical conditions such as pulmonary diseases, heart diseases, stroke, gastrointestinal disorders, kidney function disorder, diabetes mellitus, joint complaints, and cancer. Respondents were asked to indicate which medical conditions, in addition to the liver disease, they had (yes/no), and whether they had received treatment (yes/ no) for any of these medical conditions in the past 12 months. The total number of comorbidities was calculated by adding up all medical conditions for which treatment was received in the past year. Previous studies suggest that this method of self-reported comorbidity tends to be an accurate representation of actual comorbidity (Kriegsman, Penninx, van Eijk, Boeke, \& Deeg, 1996; Van den Bos, 1995). Moreover, it has been found to be applicable in a transplant population (Schulz et al., 2013).

2. The Liver Disease Symptom Index 2.0 (LDSI) (Van der Plas et al., 2004) was used to measure the severity of specific liver disease symptoms. The LDSI includes 18 items, of which nine measure the severity of liver disease-related symptoms, such as itch, jaundice, and sleepiness during the day. The other nine items measure the hindrance caused by these symptoms in terms of daily activities. All items are scored on a 5-point Likert scale ranging from 'not at all' (0) to 'to a great extent' (4). The LSDI has shown good feasibility and good test-retest reliability (Van der Plas et al., 2004). Two items, regarding depressive and anxious feelings, were removed from the analyses to avoid overlap with the outcome variables. In this study, only the severity scale of the LDSI was used. This score was calculated by summing up the scores of the remaining items.

Regarding individual characteristics, the level of personal control and coping style used were taken into account, because these are modifiable factors. In addition to these characteristics, the number of life events was examined as a potential confounder variable.

1. Personal control, the general perception of control over life, was measured using the Pearlin-Schooler Mastery Scale (Pearlin \& Schooler, 1978). The Mastery Scale measures the degree to which individuals feel they can control things that happen to them, and it consists of seven items rated on a 5 -point Likert scale $(1=$ totally disagree, 5 = totally agree). Total scores range from 7 (low personal control) to 35 (high personal control). The Mastery Scale is used in a variety of well and ill 
populations and has shown good reliability and validity (Pearlin \& Schooler, 1978). Cronbach's $\alpha$ in this study was .80 .

2. Coping style was measured using the short form of the Coping Inventory for Stressful Situations (CISS-SF). The CISS-SF measures three dimensions of responses to stressful circumstances: task-oriented, emotional, and avoidance coping. The CISS-SF consists of 21 items, where respondents can rate the extent to which they engage in various types of coping activities, when confronted with stressful situations, on a 5-point Likert scale (from $1=$ not at all to $5=$ very much) (Cohan, Jang, \& Stein, 2006). Higher scores on a subscale indicate more use of the specific coping style. In this study, the Cronbach's $\alpha$ of the subscales were as follows: .79 for the task-oriented coping scale, .82 for the emotional coping scale, and .78 for the avoidance coping scale.

3. Other Stressful life events, in addition to having end-stage liver disease, which may influence a person's life and psychological functioning, were measured using the Trauma and Life Event Self-report Inventory (TLESI) (Hovens, Bramsen, van der Ploeg, \& Reuling, 2000). The TLESI consists of a list of eleven stressful events, where a person can indicate which events happened in the past 5 years. Additional life events that had an influence on a person's life could be added. In the analyses, the number of reported life events was taken into account.

\section{Data analyses}

Distinct trajectories were identified using PROC TRAJ in SAS 9.4 (SAS Institute Inc., Cary, NC, USA), a group-based modelling strategy for analysing developmental trajectories over age or time. PROC TRAJ identifies latent clusters of individuals following a similar course of development and is able to identify time trajectories of maximally third-order polynomials in a population. Respondents are assigned to one of the identified trajectories by calculating the probability of membership in each latent cluster for each respondent using a censored normal mixture model (Jones, Nagin, \& Roeder, 2001). This means that the response variables (anxiety and depression) are normally distributed within each trajectory.

To select the best model, several criteria were used as follows: (1) The Bayesian information criterion (BIC) and the Akaike information criterion (AIC) were used to measure the relative fit of the model, with lower values indicating a better fit; (2) the posterior probabilities of group membership, the estimated probability of group membership for individuals assigned to each group, should exceed a minimum threshold of 0.7 ; and (3) an extra class of substantial size ( $>5 \%$ ) should be conceptually meaningful and represent a trajectory differing from trajectories with fewer classes (Nagin \& Odgers, 2010).

The waiting-list cohort was a dynamic cohort; subjects were being continuously enrolled in or removed from the waiting-list group (in case of transplantation, removal from the waiting list, or death) during the follow-up period. Therefore, the number of observations for each transplant candidate and the sample sizes per measurement point varied between one and eight measurements. However, PROC TRAJ can handle missing data of the type Missing at Random (MAR) and Missing Not at Random (MNAR) using maximum-likelihood estimation. To check the robustness of our findings, sensitivity analyses were performed using data from five of the eight measurements points (T0-T4). 
Cluster membership with respect to the trajectories of anxiety and depression, identified for each transplant candidate, was added to an IBM SPSS Statistics 22.0 database (SPSS Inc., Chicago, 2013), which was used for all other analyses. Descriptive statistics were used to calculate the mean scores or prevalence rates of the demographic, clinical, and individual characteristics. Univariate ordinal logistic regression (OLR) analysis was used to examine whether these characteristics were significantly related with the distinct trajectories. Characteristics that were significantly related with trajectories were entered into a multiple OLR analysis to examine the independent effect of these characteristics on the distinct trajectories using odds ratios.

To test the stability of the trajectories over time, the effect size of partial eta squared $\left(\eta_{p}^{2}\right)$ was used. Partial eta squared describes the proportion of the total variability attributable to a factor (Levine \& Hullett, 2002). GLM repeated-measures ANOVA with time as a factor was used to calculate $\eta_{p}^{2}$. Because of the small sample sizes in the measurement points $\mathrm{T} 5-\mathrm{T} 7$, these analyses were performed using the data of the measurement points T0-T4. p-value was set at .05, two-tailed, for all analyses.

\section{Results}

Of the 474 liver transplant candidates on the waiting list between October 2009 and April 2013,350 were eligible to participate in the study (Figure 1). Of these, 241 liver transplant candidates (68.9\%) agreed to participate. Liver transplant candidates not willing to participate were significantly younger ( 48.0 years, $\pm 13.6 ; p=.02$ ) than those willing to participate. Besides this, candidates with the primary diagnosis of biliary cirrhosis were more willing to participate $(76 \%, p=.048)$, whereas candidates within the group of miscellaneous diseases were less willing to participate $(54 \%, p=.03)$. Regarding sex, time since diagnosis, time on waiting list, and MELD score, no differences were found between participants and non-participants.

Two hundred and sixteen liver transplant candidates (93.1\%) responded to the baseline questionnaire (T0); 25 did not return the baseline questionnaire for several reasons (Figure 1).

During the study period, 116 of the respondents received a transplant (53.7\%), 15 respondents (6.9\%) were removed from the waiting list, and 14 respondents $(6.5 \%)$ died during the waiting-list period (Figure 1). At the end of the study, 71 respondents were still on the waiting list.

Demographic, clinical, and individual characteristics of the study population are presented in Table 1.

\section{Trajectories of anxiety during the waiting-list period}

The parameter estimates of the trajectory analysis showed that the model identifying three distinct trajectories was the best model for symptoms of anxiety (Table 2). In this model, the BIC score was the lowest, posterior probabilities exceeded the threshold of $>0.7$, and all trajectories comprised $>5 \%$ of the study population. In Figure 2 , the distinct trajectories of anxiety are depicted, in which the dotted line represents the predicted values of the cluster-specific trajectories, and the solid line, the observed average values. The three distinctive trajectories of anxiety were characterized by the following: (1) a group with average symptom scores below the clinical level, comprising $51.3 \%(n=118)$ of the respondents; (2) a group with average symptom scores slightly above the clinical 


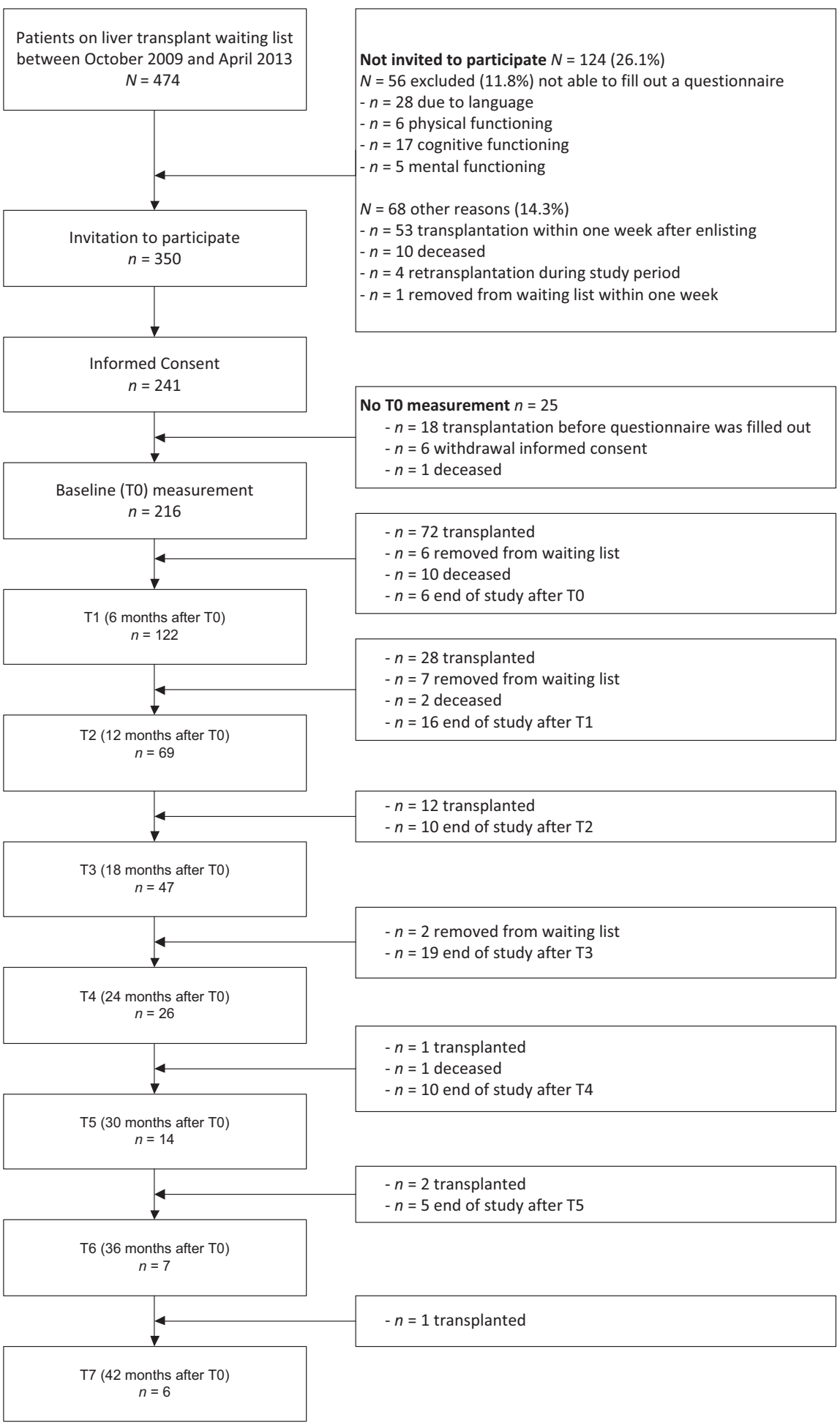

Figure I. Study inclusion flow diagram. 
Table I. Baseline demographic, clinical, and individual characteristics of the study population

\begin{tabular}{lc}
\hline & All \\
Characteristic & $N=216$ \\
\hline$N(\%)$ & \\
Gender: male & $144(66.7)$ \\
Marital status: with partner & $168(87.8)$ \\
Educational level & \\
Low & $47(21.8)$ \\
Moderate & $96(44.4)$ \\
High & $73(33.8)$ \\
Employment status: paid job & $64(29.6)$ \\
Nationality: Dutch & $200(92.6)$ \\
Primary disease & \\
Biliary cirrhosis & $78(36.1)$ \\
Alcoholic cirrhosis & $51(23.6)$ \\
Metabolic disorder & $24(11.1)$ \\
Viral hepatitis & $28(13.0)$ \\
Cirrhosis of unknown origin & $18(8.3)$ \\
Miscellaneous & $17(7.8)$ \\
Hepato Cellular carcinoma & $34(15.7)$ \\
Mean (SD) & \\
Age (in years) & $51.6(11.3)$ \\
Number of comorbidities & $1.9(1.6)$ \\
Time since diagnosis (in years) & $5.8(6.3)$ \\
Time on waiting list (in months) & $7.8(13.9)$ \\
MELD score & $13.3(5.3)$ \\
LDSI score & $9.5(5.4)$ \\
Personal control & $23.9(5.4)$ \\
Coping style & $19.2(6.5)$ \\
Emotional coping & $25.1(4.3)$ \\
Task-oriented coping & $17.1(5.0)$ \\
Avoidance coping & $1.6(1.3)$ \\
Number of life events & \\
\hline &
\end{tabular}

level, comprising 33.5\% ( $n=67)$ of the respondents; and (3) a group with average symptom scores high above clinical level, comprising $15.2 \%(n=31)$ of the respondents. Sensitivity analyses using data of T0-T4 revealed three similar distinctive trajectories (BIC: 2 clusters: $1292.91 ; 3$ clusters: 1288.92 ; 4 clusters: 1295.37), with an overlap in group membership in $94.4 \%$ of the cases. Regarding the stability of the trajectories over time, the effect sizes $\left(\eta_{p}^{2}\right)$ were, respectively, .08 for trajectory $1, .15$ for trajectory 2 , and .20 for trajectory 3. This indicates that time accounted for $8-20 \%$ of the variability in anxiety scores within the trajectories.

Variables related with the trajectories of anxiety

As shown in Table 3, univariate ordinal logistic regression analyses revealed that the distinctive trajectories were independently related with the variables: educational level, the LDSI score, personal control, emotional coping, task-oriented coping, and the number of life events. Investigating the effects of these variables simultaneously on trajectory 
Table 2. Parameters used for model selection regarding trajectories of symptoms of anxiety and depression

\begin{tabular}{|c|c|c|c|c|c|c|c|c|}
\hline \multirow[b]{2}{*}{ Model } & \multirow[b]{2}{*}{$\mathrm{BIC}$} & \multirow[b]{2}{*}{ AIC } & \multirow[b]{2}{*}{ Posterior probabilities } & \multicolumn{5}{|c|}{$\%$} \\
\hline & & & & I & 2 & 3 & 4 & 5 \\
\hline \multicolumn{9}{|c|}{ Symptoms of anxiety } \\
\hline 2 & I355.64 & | 338.77 & $0.89-0.93$ & 62.6 & 37.4 & - & - & - \\
\hline 3 & 1349.24 & 1323.93 & $0.77-0.87$ & 51.3 & 33.5 & 15.2 & - & - \\
\hline 4 & 1354.92 & 1321.16 & $0.69-0.86$ & 49.1 & 6.8 & 29.2 & 14.9 & - \\
\hline \multicolumn{9}{|c|}{ Symptoms of depression } \\
\hline 2 & 1860.24 & 1843.36 & $0.89-0.94$ & 71.1 & 28.9 & - & - & - \\
\hline 3 & 1835.48 & 1810.17 & $0.84-0.91$ & 75.5 & 35.0 & 7.6 & - & - \\
\hline 4 & 1824.75 & 1791.00 & $0.77-0.92$ & 22.7 & 43.9 & 27.7 & 5.7 & - \\
\hline 5 & 1833.85 & 1791.66 & $0.64-0.91$ & 21.0 & 35.9 & 12.0 & 26.0 & 5.1 \\
\hline
\end{tabular}

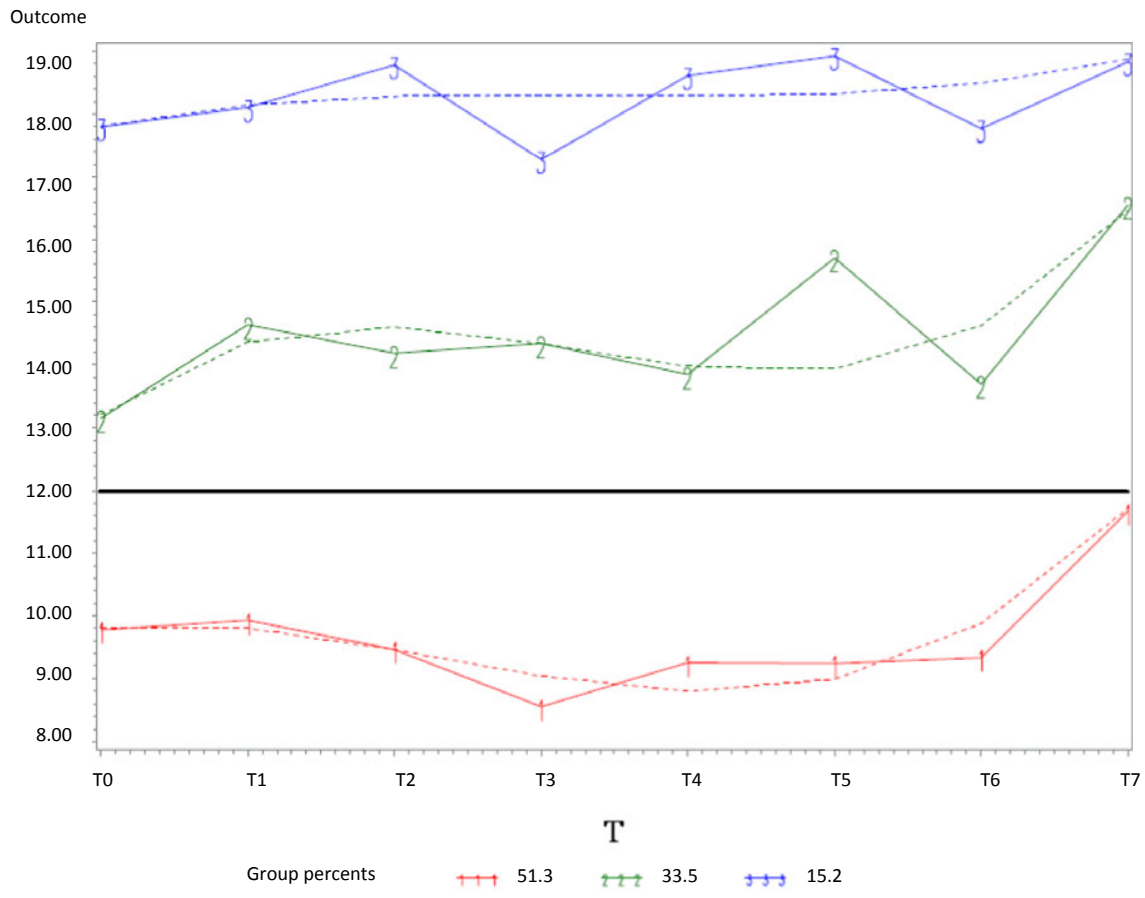

Figure 2. Distinct trajectories of symptoms of anxiety of liver transplant candidates during the waiting list period. Note. The bold black line represents the cut-off value $(\geq 12)$ of the clinical level of symptoms of anxiety. T0 $=$ baseline measurement, $\mathrm{TI}=6$ months after TO, T2 $=12$ months after T0, T3 $=18$ months after T0, T4 $=24$ months after, T5 $=30$ months after T0, T6 $=36$ months after T0, T7 = 42 months after T0. [Colour figure can be viewed at wileyonlinelibrary.com]

membership, using multiple ordinal logistic regression analysis, showed that educational level and the number of life events do not seem to help classify subjects when LDSI, personal control, emotional coping, and task-oriented coping are already provided 
Table 3. Demographic, clinical, and individual characteristics of respondents within the distinct trajectories of anxiety

\begin{tabular}{|c|c|c|c|c|}
\hline & $\begin{array}{c}\text { Trajectory I } \\
\text { Anxiety below } \\
\text { clinical level } \\
n=118\end{array}$ & $\begin{array}{c}\text { Trajectory } 2 \\
\text { Anxiety slightly } \\
\text { above clinical level } \\
n=67\end{array}$ & $\begin{array}{c}\text { Trajectory } 3 \\
\text { Anxiety high } \\
\text { above clinical level } \\
n=31\end{array}$ & $p$-Value \\
\hline \multicolumn{5}{|l|}{$n / \%$} \\
\hline Gender: Male & $78(66.1)$ & $46(68.7)$ & $20(64.5)$ & .94 \\
\hline Marital status: Partner & $91(77.1)$ & $53(79.1)$ & $24(77.4)$ & .85 \\
\hline \multicolumn{5}{|l|}{ Educational level } \\
\hline Low & $23(19.5)$ & II (I6.4) & $13(4 \mid .9)$ & .30 \\
\hline Moderate & $57(48.3)$ & $31(46.3)$ & $8(25.8)$ & .04 \\
\hline High & $38(32.2)$ & $25(37.3)$ & $10(32.3)$ & Ref. \\
\hline Currently employed: Paid job & $38(32.2)$ & $22(32.8)$ & $4(12.9)$ & .17 \\
\hline \multicolumn{5}{|l|}{ Primary disease } \\
\hline Biliary cirrhosis & $45(38.1)$ & $25(37.3)$ & $8(25.8)$ & .48 \\
\hline Alcoholic cirrhosis & $29(24.6)$ & $16(23.9)$ & $6(19.4)$ & .63 \\
\hline Metabolic disorder & II (9.3) & $8(11.9)$ & $5(16.1)$ & .48 \\
\hline Viral hepatitis & 14 (I I.9) & $6(9.0)$ & $8(25.8)$ & .21 \\
\hline Cirrhosis of unknown origin & $8(6.8)$ & $6(9.0)$ & $4(12.9)$ & .29 \\
\hline Miscellaneous & II (9.3) & $6(9.0)$ & - & .25 \\
\hline Hepato Cellular Carcinoma & $21(17.8)$ & $10(14.5)$ & $3(9.7)$ & .30 \\
\hline \multicolumn{5}{|l|}{ Mean $(S D)$} \\
\hline Age & $51.9(11.3)$ & $51.1(11.7)$ & $51.8(11.0)$ & .79 \\
\hline Number of comorbidities & $1.7(1.4)$ & $2.2(1.9)$ & $2.2(1.5)$ & .06 \\
\hline Time since diagnosis (in years) & $6.4(7.0)$ & $5.0(4.8)$ & $5.2(5.8)$ & .12 \\
\hline Time on waiting list (in months) & $6.9(13.1)$ & $7.9(15.0)$ & $9.5(14.6)$ & .36 \\
\hline MELD score & $13.3(5.5)$ & $12.9(5.4)$ & $14.5(4.5)$ & .59 \\
\hline LDSI score & $7.7(4.9)$ & $10.5(4.3)$ & $14.0(5.7)$ & $<.001$ \\
\hline Personal control & $26.1(4.8)$ & $22.3(5.0)$ & 19.1 (4.4) & $<.001$ \\
\hline \multicolumn{5}{|l|}{ Coping style } \\
\hline Emotional coping & $16.8(5.4)$ & $21.3(6.8)$ & $23.5(5.9)$ & $<.001$ \\
\hline Task-oriented coping & $25.9(4.2)$ & $25.0(4.0)$ & $22.6(4.3)$ & $<.001$ \\
\hline Avoidance coping & $16.6(5.4)$ & $17.6(4.7)$ & $17.4(3.8)$ & .22 \\
\hline Number of life events & $\mathrm{I} .4(\mathrm{I} . \mathrm{I})$ & $\mathrm{I} .7(\mathrm{I} .4)$ & $2.1(1.5)$ & .01 \\
\hline
\end{tabular}

Note. MELD = Model for End-stage Liver Disease; LDSI = Liver disease Symptom Index; ref. = reference category.

Bold values are significant.

(Table 4). The results of the OLR analysis showed that a unit increase in LDSI score $(\mathrm{OR}=1.16, \mathrm{CI} 1.09-1.23)$ and a unit increase in emotional coping score $(\mathrm{OR}=1.13, \mathrm{CI}$ 1.07-1.19) were related with an increase in the odds of membership in the trajectories with higher levels of anxiety, while a unit increase in personal control score $(\mathrm{OR}=0.89$, CI $0.84-0.95)$ and a unit increase in the task-oriented coping score (OR $=0.89, \mathrm{CI} 0.82-0.96)$ reduced the odds of membership in trajectories with higher levels of symptoms of anxiety.

Trajectories of depression during the waiting-list period

Regarding depressive symptoms, the model with four distinct trajectories was found to be the best model, with the lowest BIC score, posterior probabilities $>0.7$, and the smallest 
group still comprised $>5 \%$ of the study population (Table 2). In Figure 3, the trajectory analyses of symptoms of depression are depicted. The four distinctive trajectories of depression identified can be characterized as follows: (1) a group with average symptom scores for depression below the clinical level, comprising $22.7 \%(n=36)$ of the respondents; (2) a group with average symptom scores for depression slightly below clinical level, comprising $43.9 \%(n=104)$ of the respondents; (3) a group with average symptom scores for depression slightly above clinical level, comprising $27.7 \%(n=66)$ of the respondents; and (4) a group with average symptom scores for depression high above the clinical level, comprising $5.7 \%(n=10)$ of the respondents. Sensitivity analyses, using data from T0-T4, revealed four similar distinctive trajectories (three clusters: 1746.55; four clusters: 1740.71 ; five clusters: 1750.09$)$, with an overlap in group membership in $89.4 \%$ of the cases. Regarding the stability of the trajectories over time, the effect sizes $\left(\eta_{p}^{2}\right)$ were, respectively, .07 for trajectory $1, .04$ for trajectory $2, .03$ for trajectory 3 , and .20 for trajectory 4 . This indicates that time accounted for $3 \%$ to $20 \%$ of the variability in depression scores within the trajectories.

\section{Variables related with the trajectories of depression}

As shown in Table 5, univariate OLR revealed that the trajectories of depression were independently related with the variables: employment status, presence of hepatocellular carcinoma, number of comorbidities, MELD score, the LDSI score, personal control, emotional coping, and task-oriented coping. Investigating the effects of these variables simultaneously on trajectory membership, with multiple OLR analyses, showed that employment status, the presence of hepatocellular carcinoma, the number of comorbidities, and the MELD score do not seem to help classify subjects, when LDSI, personal control, emotional coping, and task-oriented coping are already provided (Table 6 ). The results of the OLR analysis showed that a unit increase in the LDSI score (OR $=1.23$, CI 1.15-1.32) and a unit increase in the emotional coping score (OR $=1.13$, CI 1.07-1.18) were related with an increase in the odds of membership in trajectories with higher levels

Table 4. Unstandardized estimates, odds ratios, and $95 \%$ confidence intervals of characteristics related with the distinct trajectories of anxiety

\begin{tabular}{lccccc}
\hline & & & & \multicolumn{2}{c}{$\begin{array}{c}\text { 95\% Confidence } \\
\text { Interval }\end{array}$} \\
\cline { 5 - 7 } Variable & Estimate & $p$-Value & Odds ratio & Lower & Upper \\
\hline Low educational level & 0.14 & .73 & 1.15 & 0.51 & 2.64 \\
Middle educational level & -0.68 & .09 & 0.51 & 0.23 & 1.11 \\
High educational level & Reference & & & & 1.09 \\
LDSI score & 0.14 & $<.01$ & 1.16 & 1.23 \\
Personal control & -0.11 & $<.01$ & 0.89 & 0.84 & 0.95 \\
Emotional coping style & 0.12 & $<.01$ & 1.13 & 1.07 & 1.19 \\
Task-oriented coping style & -0.12 & $<.01$ & 0.89 & 0.82 & 0.96 \\
Number of life events & 0.19 & .11 & 1.21 & 0.96 & 1.53 \\
\hline
\end{tabular}

Notes. LDSI $=$ Liver Disease Symptom Index. pseudo- $R^{2}=0.40$ (Cox \& Snell), 0.47 (Nagelkerke); Model $\chi^{2}(423)=403.27, p=.75$.

Bold values are significant. 


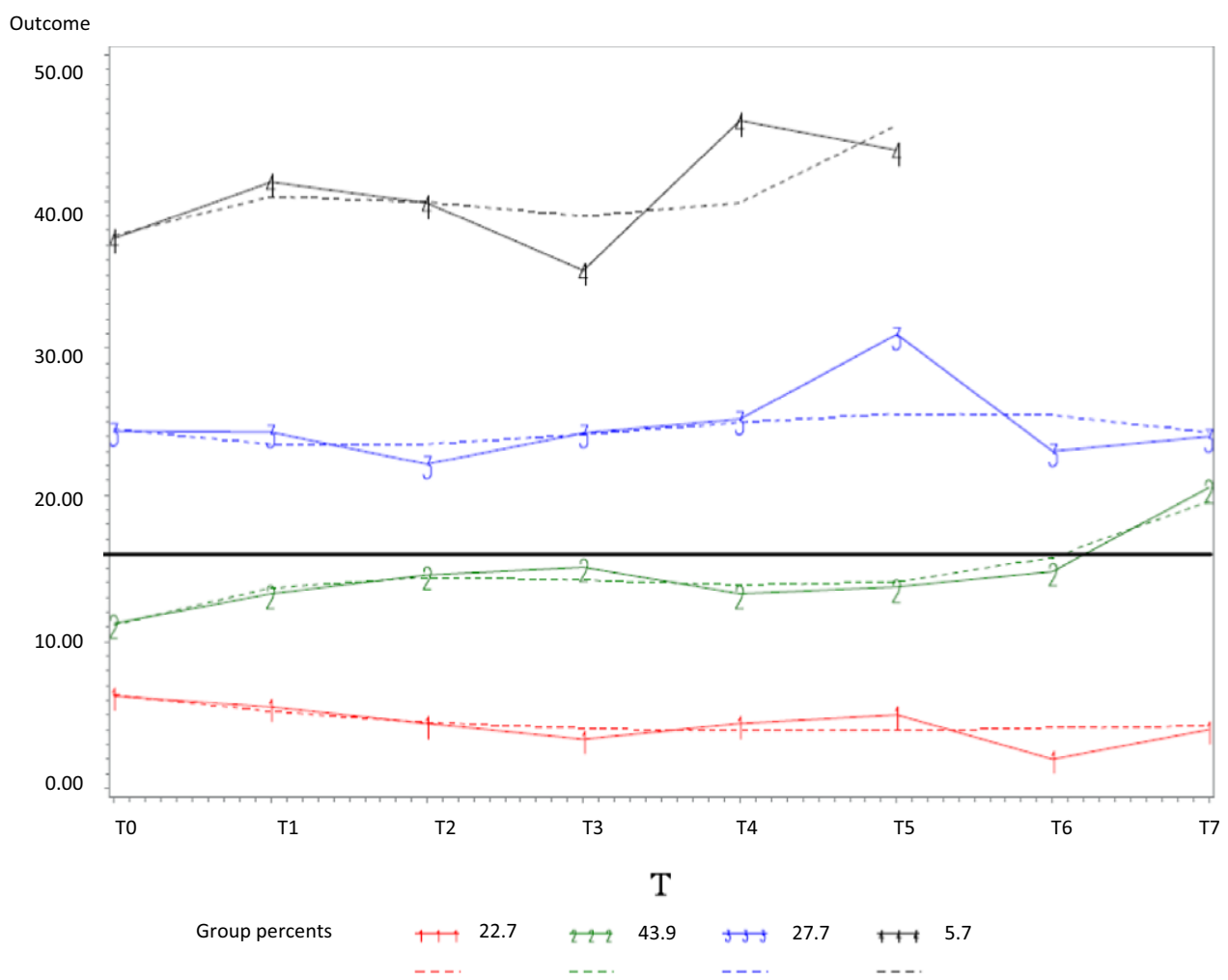

Figure 3. Distinct trajectories of symptoms of depression of liver transplant candidates during the waiting-list period. Note. The bold black line represents the cut-off value $(\geq 16)$ of the clinical level of symptoms of depression. T0 $=$ baseline measurement, $\mathrm{TI}=6$ months after T0, T2 $=12$ months after T0, T3 = 18 months after T0, T4 = 24 months after, T5 = 30 months after T0, T6 = 36 months after $\mathrm{TO}, \mathrm{T7}=42$ months after T0. [Colour figure can be viewed at wileyonlinelibrary.com]

of depression, whereas a unit increase in the personal control score $(\mathrm{OR}=0.84$, CI $0.78-$ $0.90)$ and a unit increase in the task-oriented coping score $(\mathrm{OR}=0.91, \mathrm{CI} 0.85-0.98)$ were related with a decrease in the odds of membership in the trajectories with higher levels of depressive symptoms.

\section{Discussion}

This study showed that distinct trajectories of anxiety and depression are present in liver transplant candidates. Regarding symptoms of anxiety, three distinct trajectories were identified as follows: 1) below clinical level, 2) slightly above clinical level, and 3) high above clinical level, comprising, respectively, 51\%, 34\%, and 15\% of the respondents. With respect to depressive symptoms, four distinct trajectories were identified as follows: (1) below clinical level, (2) slightly below clinical level, (3) slightly above clinical level, and (4) high above clinical level, comprising, respectively, 23\%, 34\%, 28\%, and 6\% of the respondents. All trajectories were stable over time. Time accounted for $8-20 \%$ of the variance in scores within the trajectories of anxiety and for 3-20\% in the variance of scores in the trajectories of depression. The stability of the trajectories over time seems to 
Table 5. Demographic, clinical, and individual characteristics of respondents within the distinct trajectories of depression

\begin{tabular}{|c|c|c|c|c|c|}
\hline & $\begin{array}{l}\text { Trajectory I } \\
\text { Depression } \\
\text { below } \\
\text { clinical level } \\
n=36\end{array}$ & $\begin{array}{l}\text { Trajectory } 2 \\
\text { Depression } \\
\text { slightly below } \\
\text { clinical level } \\
n=104\end{array}$ & $\begin{array}{c}\text { Trajectory } 3 \\
\text { Depression } \\
\text { slightly above } \\
\text { clinical level } \\
n=66\end{array}$ & $\begin{array}{l}\text { Trajectory } 4 \\
\text { Depression } \\
\text { high above } \\
\text { clinical level } \\
n=10\end{array}$ & $p$-Value \\
\hline \multicolumn{6}{|l|}{$n(\%)$} \\
\hline Gender: Male & $21(58.3)$ & 7I (68.3) & $45(68.2)$ & $7(70.0)$ & .40 \\
\hline Marital status: Partner & $28(77.8)$ & 81 (77.9) & $52(78.8)$ & $7(70.0)$ & .91 \\
\hline \multicolumn{6}{|l|}{ Educational level } \\
\hline Low & $9(25.0)$ & $17(16.3)$ & $16(24.2)$ & $5(50.0)$ & .45 \\
\hline Moderate & $16(44.4)$ & $52(50.0)$ & $24(36.4)$ & $4(40.0)$ & .25 \\
\hline High & II (30.6) & 35 (33.7) & $26(39.4)$ & I (10.0) & Ref. \\
\hline Employment status: Paid job & $16(44.4)$ & $35(33.7)$ & $13(19.7)$ & $0(0)$ & .001 \\
\hline \multicolumn{6}{|l|}{ Primary disease } \\
\hline Biliary cirrhosis & $15(4 \mid .7)$ & $37(35.6)$ & $24(36.4)$ & $2(20.0)$ & .53 \\
\hline Alcoholic cirrhosis & $9(25.0)$ & $23(22.1)$ & $16(24.2)$ & $3(30.0)$ & .82 \\
\hline Metabolic disorder & $5(13.9)$ & $10(9.6)$ & $5(7.6)$ & $4(40.0)$ & .92 \\
\hline Viral hepatitis & $3(8.3)$ & $14(13.5)$ & $10(15.7)$ & I (10.0) & .49 \\
\hline Cirrhosis of unknown origin & $\mathrm{I}(2.8)$ & $10(9.6)$ & $7(10.6)$ & $0(0)$ & .52 \\
\hline Miscellaneous & $3(8.3)$ & $10(9.6)$ & $4(6.1)$ & $0(0)$ & .38 \\
\hline Hepato Cellular Carcinoma & $9(25.0)$ & $20(19.2)$ & $4(6.1)$ & $I(10.0)$ & .01 \\
\hline \multicolumn{6}{|l|}{ Mean $(S D)$} \\
\hline Age (in years) & $50.6(1 \mathrm{I} .2)$ & $52.2(12.0)$ & $50.9(11.1)$ & $54.2(5.7)$ & .89 \\
\hline Number of comorbidities & $\mathrm{I} .4(\mathrm{I} .1)$ & $1.9(1.6)$ & $1.9(1.7)$ & $3.6(1.6)$ & .01 \\
\hline Time since diagnosis (in years) & $6.0(6.0)$ & $6.2(6.7)$ & $5.3(5.7)$ & $4.1(6.5)$ & .32 \\
\hline $\begin{array}{l}\text { Time on waiting list } \\
\text { (in months) }\end{array}$ & $9.4(16.2)$ & $5.7(11.7)$ & $9.5(16.1)$ & $8.4(7.3)$ & .53 \\
\hline MELD score & II.I (4.9) & I3.5 (5.6) & 14.3 (4.9) & I $3.7(5.4)$ & .01 \\
\hline LDSI score & $4.8(3.9)$ & $8.5(4.2)$ & $13.0(5.3)$ & I3.I (4.0) & $<.01$ \\
\hline Personal control & $28.1(4.2)$ & $25.1(4.5)$ & $20.9(4.6)$ & $15.5(4.7)$ & $<.01$ \\
\hline \multicolumn{6}{|l|}{ Coping style } \\
\hline Emotional coping & $16.3(4.8)$ & I7.5 (5.5) & $22.3(6.4)$ & $27.4(7.2)$ & $<.01$ \\
\hline Task-oriented coping & $26.8(3.9)$ & $25.4(4.2)$ & $24.3(4.3)$ & $21.9(4.6)$ & $<.01$ \\
\hline Avoidance coping & I7.5 (5.6) & I7.0 (5.I) & I7.I (4.6) & I $5.7(5.0)$ & .55 \\
\hline Number of life events & I.3 (I.I) & $1.5(1.2)$ & $\mathrm{I} .8(1.4)$ & $\mathrm{I} .5(\mathrm{I} .4)$ & .09 \\
\hline
\end{tabular}

Note. MELD = Model for End-stage Liver Disease; LDSI = Liver Disease Symptom Index; ref. = reference category.

Bold values are significant.

indicate that the baseline measurement is indicative of the level of depression and anxiety of liver transplant candidates during the waiting-list period.

These results confirmed two of our hypotheses, namely that the majority of transplant candidates would show low symptom levels of anxiety and depression and that a small subset would show high symptom levels. These findings are in line with studies analysing trajectories in other patient groups (Henselmans et al., 2010; Lam et al., 2013; Ng et al., 2015; Yohannes et al., 2016). However, in contrast to other studies, our third hypothesis, that a subset of the transplant candidates would show an increase in symptom level, was 
Table 6. Unstandardized estimates, odds ratios, and $95 \%$ confidence intervals of characteristics related with the distinct trajectories of depression

\begin{tabular}{lcccccc}
\hline & & & & \multicolumn{2}{c}{$\begin{array}{c}9 \% \text { Confidence } \\
\text { Interval }\end{array}$} \\
\cline { 5 - 7 } Variable & & & & & & \\
\cline { 5 - 7 } & Estimate & $p$-Value & Odds Ratio & Lower & Upper \\
\hline Employment (if yes) & -0.31 & .36 & 0.73 & 0.38 & 1.42 \\
Hepatocellular carcinoma (if yes) & -0.24 & .58 & 0.79 & 0.35 & 1.80 \\
Number of comorbidities & 0.02 & .87 & 1.02 & 0.84 & 1.22 \\
MELD score & 0.03 & .34 & 1.02 & 0.97 & 1.08 \\
LDSI score & 0.22 & .00 & 1.23 & 1.15 & 1.32 \\
Personal control & -0.18 & .00 & 0.84 & 0.78 & 0.90 \\
Emotional coping style & 0.12 & .00 & 1.13 & 1.07 & 1.18 \\
Task-oriented coping style & -0.09 & .01 & 0.91 & 0.85 & 0.98 \\
\hline
\end{tabular}

Notes. MELD = Model for End-stage Liver Disease; LDSI = Liver Disease Symptom Index. pseudo- $R^{2}=0.53$ (Cox \& Snell), 0.58 (Nagelkerke); Model $\chi^{2}(639)=424.44, p=1.000$.

Bold values are significant.

not confirmed. Instead, we found that a substantial part of the transplant candidates showed stable symptom levels slightly above the clinically relevant level of anxiety and depression. This might be related to the ongoing feelings of uncertainty during the waiting period for a donor organ.

Of all the demographic, clinical, and individual characteristics examined, four variables were found to be independently related with both the trajectories of anxiety and depression: the LDSI score, personal control, and emotional and task-oriented coping. In contrast to studies that have analysed associations at a group level (Corruble et al., 2011; Lopez-Navas et al., 2011; Sainz-Barriga et al., 2005; Santos et al., 2010), we found no relations between demographic characteristics, such as age, sex, marital status, and employment status and the trajectories of either anxiety or depression. However, these finding are in line with other studies examining variables related with trajectories of anxiety and depression in other patient groups, in which also clinical and individual variables, such as physical symptoms and coping strategies, were found to be predictive of trajectories of psychological distress and no relations were found with demographic variables (Bonanno, Kennedy, Galatzer-Levy, Lude, \& Elfström, 2012; Henselmans et al., 2010; Lam et al., 2013; Van den Broek et al., 2014).

Regarding clinical characteristics, only the LDSI score, the severity of liver disease symptoms as perceived by the transplant candidate, was found to be related with the trajectories of anxiety and depression. Respondents who perceived the liver disease symptoms as more severe had a higher probability of being in the trajectories with higher levels of anxiety and depression. This finding emphasizes that adequate management of liver disease symptoms is necessary. However, the LDSI is a subjective measurement of disease severity, and this finding was not supported by an objective measurement of disease severity, such as the MELD score. This may imply that altering the cognitive appraisal of disease symptoms by giving adequate procedural and sensory information about liver disease symptoms and possible self-management strategies may help transplant candidates to cope with their deteriorating health. However, it is acknowledged that some liver disease symptoms (e.g., itch and fatigue) are hard to treat. Therefore, this aspect needs to be examined in future research. 
The individual characteristics of personal control and coping seem to play a major role in the development and maintenance of symptoms of anxiety and depression. Transplant candidates with a lower level of personal control, who feel that they have no control over the things that happen to them, and those who make more use of emotional coping, were more likely to be in the trajectories with high symptom levels of both anxiety and depression. Transplant candidates with a high level of personal control and who make more use of task-oriented coping, on the other hand, seem to be less anxious and depressed. Therefore, interventions aimed at empowering transplant candidates by strengthening coping skills or sense of control may help to reduce symptoms of anxiety and depression during the waiting-list period. However, evidence regarding effective psychosocial interventions in transplant candidates is lacking (Cupples et al., 2006; Engle, 2001). So far, only a few studies, reporting (preliminary) findings regarding psychosocial interventions in transplant candidates and recipients, showed that this may be effective in reducing distress (Dew et al., 2004; Hsiao et al., 2016; Napolitano et al., 2002; Reilly-Spong, Reibel, Pearson, Koppa, \& Gross, 2015). In future studies, the effectiveness of psychosocial interventions to address psychological problems in transplant candidates needs to be examined.

The clinical implication of our study is that identifying transplant candidates at risk of psychological distress is warranted early in the transplant process by the use of routine screening of psychological problems as well as variables of influence on the psychological functioning of transplant candidates. Although the importance of screening for psychological problems has been widely recognized (Olbrisch, Benedict, Ashe, \& Levenson, 2002), common practice may vary between transplant centres, and psychosocial screening is a less standardized procedure (Maldonado et al., 2012). In the literature, several instruments to perform a structured psychosocial assessment of transplant candidates have been described, of which the 'Stanford Integrated Psychosocial Assessment for Transplantation' (SIPAT) (Maldonado et al., 2012) seems the most promising. The SIPAT assesses psychological functioning as well as risk factors, such as coping style and individual traits, of influence on adverse outcomes after transplantation. Based on the psychosocial screening, interventions tailored to the patient's needs, such as supportive counselling, mindfulness based stress reduction, or coping skills training, can be undertaken to enhance the psychological wellbeing of transplant candidates. In addition to psychosocial interventions aimed at reducing distress, referral for psychological or psychiatric counselling may contribute to better psychological well-being during the waiting-list period, which ultimately may in turn contribute to better outcomes after transplantation.

The strength of our study was its prospective, longitudinal, and multicentre design which made it possible to study the evolution of psychological problems over time. The overall sample size $(n=216)$ was reasonable, and the response rate of $69 \%$ was satisfactory. Furthermore, a full range of related variables (demographic, clinical, and individual) was examined. However, the sample size was relatively small for trajectory analysis. In addition, the use of a dynamic cohort led, resulting in non-random subject dropout, could have influenced the results of our study. The generalizability of our results may, therefore, be limited, and replication of our findings in larger sample sizes is warranted.

In conclusion, distinct trajectories of symptoms of anxiety and depression were present in liver transplant candidates. The trajectories with symptom levels above clinical relevant levels for anxiety or depression comprised, respectively, $49 \%$ and $34 \%$ of the respondents. The stability of these trajectories over time seems to indicate that the baseline measurement is indicative of the course of symptoms of anxiety and depression 
during the waiting-list period. Experiencing more liver disease symptoms, a lower level of personal control, making more use of emotional coping, and making less use of taskoriented coping increased the odds of membership in trajectories with higher symptom levels for both the trajectories of anxiety and of depression. Therefore, screening of psychological problems and related risk factors early in the transplant process - if not already established - is recommended. Subsequently, appropriate interventions aimed at reducing distress should be undertaken to optimize the psychological well-being of the transplant candidate. However, evidence regarding the effectiveness of psychosocial interventions in organ transplant candidates is lacking and needs to be studied in future research.

\section{Acknowledgements}

The authors kindly thank Roy E. Stewart for his contribution to the revision of the manuscript.

\section{Conflict of interest}

All authors declare no conflict of interest.

\section{References}

Bonanno, G. A., Kennedy, P., Galatzer-Levy, I., Lude, P., \& Elfström, M. L. (2012). Trajectories of resilience, depression, and anxiety following spinal cord injury. Rebabilitation Psychology, 57 (3), 236-247. https://doi.org/10.1037/a0029256

Bouma, J., Ranchor, A. V., Sanderman, R., \& Van Sonderen, E. (1995). Measurement of depressive symptoms with the CES-D. A manual (in Dutch). Groningen, The Netherlands: Northern Center of Health Research. ISBN 9072156250.

Caccamo, L., Azara, V., Doglia, M., Sessini, M., Rossi, G., Gala, C., \& Fassati, L. R. (2001). Longitudinal prospective measurement of the quality of life before and after liver transplantation among adults. Transplantation Proceedings, 33(1-2), 1880-1881. https://doi.org/10.1016/S00411345(00)02734-2

Chiu, N. M., Chen, C. L., \& Cheng, A. T. (2009). Psychiatric consultation for post-liver-transplantation patients. Psychiatry and Clinical Neurosciences, 63(4), 471-477. https://doi.org/10.1111/j. 1440-1819.2009.01987.x

Cohan, S. L., Jang, K. L., \& Stein, M. B. (2006). Confirmatory factor analysis of a short form of the coping inventory for stressful situations. Journal of Clinical Psychology, 62(3), 273-283. https://doi.org/10.1002/jclp.20211

Corruble, E., Barry, C., Varescon, I., Falissard, B., Castaing, D., \& Samuel, D. (2011). Depressive symptoms predict long-term mortality after liver transplantation. Journal of Psychosomatic Research, 71(1), 32-37. https://doi.org/10.1016/j.jpsychores.2010.12.008

Corruble, E., Durrbach, A., Charpentier, B., Lang, P., Amidi, S., Dezamis, A., . . Falissard, B. (2010). Progressive increase of anxiety and depression in patients waiting for a kidney transplantation. Behavioral Medicine (Washington, D.C.), 36(1), 32-36 https://doi.org/10.1080/ 08964280903521339

Cupples, S., Dew, M. A., Grady, K. L., De Geest, S., Dobbels, F., Lanuza, D., \& Paris, W. (2006). Report of the psychosocial outcomes workgroup of the nursing and social sciences council of the international society for heart and lung transplantation: Present status of research on psychosocial outcomes in cardiothoracic transplantation: Review and recommendations for the field. The Journal of Heart and Lung Transplantation: The Official Publication of the 
International Society for Heart Transplantation, 25(6), 716-725. https://doi.org/10.1016/j. healun.2006.02.005

Dew, M. A., Goycoolea, J. M., Harris, R. C., Lee, A., Zomak, R., Dunbar-Jacob, J., . . Kormos, R. L. (2004). An internet-based intervention to improve psychosocial outcomes in heart transplant recipients and family caregivers: Development and evaluation. The Journal of Heart and Lung Transplantation: The Official Publication of the International Society for Heart Transplantation, 23(6), 745-758. https://doi.org/10.1016/j.healun.2003.07.002

Dew, M. A., Simmons, R. G., Roth, L. H., Schulberg, H. C., Thompson, M. E., Armitage, J. M., \& Griffith, B. P. (1994). Psychosocial predictors of vulnerability to distress in the year following heart transplantation. Psychological Medicine, 24(4), 929-945. https://doi.org/10.1017/ S0033291700029020

Dutch Transplantation Society (2015). Annual report 2014. Leiden, The Netherlands: Dutch Transplantation Society.

Engle, D. (2001). Psychosocial aspects of the organ transplant experience: What has been established and what we need for the future. Journal of Clinical Psychology, 57(4), 521-549. https://doi.org/10.1002/jclp.1027

Errichiello, L., Picozzi, D., \& de Notaris, E. B. (2014). Prevalence of psychiatric disorders and suicidal ideation in liver transplanted patients: A cross-sectional study. Clinics and Research in Hepatology and Gastroenterology, 38(1), 55-62. https://doi.org/10.1016/j.clinre.2013.07.010

Eurotransplant International Foundation (2015). Annual report 2013. Leiden, The Netherlands: Eurotransplant International Foundation.

Goetzmann, L., Wagner-Huber, R., Klaghofer, R., Muellhaupt, B., Clavien, P. A., Buddeberg, C., \& Scheuer, E. (2006). Waiting for a liver transplant: Psychosocial well-being, spirituality, and need for counselling. Transplantation Proceedings, 38(9), 2931-2936. https://doi.org/10.1016/j.tra nsproceed.2006.08.171

Guimaro, M. S., Lacerda, S. S., Karam, C. H., Ferraz-Neto, B. H., \& Andreoli, P. B. (2008). Psychosocial profile of patients on the liver transplant list. Transplantation Proceedings, 40(3), 782-784. https://doi.org/10.1016/j.transproceed.2008.02.040

Gutteling, J. J., de Man, R. A., Busschbach, J. J., \& Darlington, A. S. (2007). Health-related quality of life and psychological correlates in patients listed for liver transplantation. Hepatology International, 1(4), 437-443. https://doi.org/10.1007/s12072-007-9035-0

Haugh, K. H., \& Salyer, J. (2007). Needs of patients and families during the wait for a donor heart. Heart \& Lung: The Journal of Critical Care, 36(5), 319-329. https://doi.org/10.1016/j.hrtlng. 2006.11.003

Henselmans, I., Helgeson, V. S., Seltman, H., de Vries, J., Sanderman, R., \& Ranchor, A. V. (2010). Identification and prediction of distress trajectories in the first year after a breast cancer diagnosis. Health Psychology, 29(2), 160-168. https://doi.org/10.1037/a0017806

Hovens, J. E., Bramsen, I., van der Ploeg, H. M., \& Reuling, I. E. (2000). Test-retest reliability of the trauma and life events self-report inventory. Psychological Reports, 87(3 Pt 1), 750-752. https:// doi.org/10.2466/pr0.2000.87.3.750

Hsiao, C., Lin, L., Su, Y., Yeh, S., Lee, L., \& Tsai, F. (2016). The effects of an empowerment intervention on renal transplant recipients: A randomized controlled trial. The Journal of Nursing Research: 24(3), 201-210. https://doi.org/10.1097/jnr.0000000000000115

Jones, B. L., Nagin, D. S., \& Roeder, K. (2001). A SAS procedure based on mixture models for estimating developmental trajectories. Sociological Methods \& Research, 29(3), 374-393.

Kriegsman, D. M., Penninx, B. W., van Eijk, J. T., Boeke, A. J., \& Deeg, D. J. (1996). Self-reports and general practitioner information on the presence of chronic diseases in community dwelling elderly. A study on the accuracy of patients' self-reports and on determinants of inaccuracy. Journal of Clinical Epidemiology, 49(12), 1407-1417. https://doi.org/10.1016/S0895-4356 (96)00274-0

Kugler, C., Gottlieb, J., Warnecke, G., Schwarz, A., Weissenborn, K., Barg-Hock, H., .. Haller, H. (2013). Health-related quality of life after solid organ transplantation: A prospective, multiorgan 
cohort study. Transplantation, 96(3), 316-323. https://doi.org/10.1097/TP.0b013e $31829853 \mathrm{eb}$

Lam, W. W. T., Soong, I., Yau, T. K., Wong, K. Y., Tsang, J., Yeo, W., \& Fielding, R. (2013). The evolution of psychological distress trajectories in women diagnosed with advanced breast cancer: A longitudinal study. Psycho-Oncology, 22(12), 2831-2839. https://doi.org/10.1002/ pon. 3361

Levine, T. R., \& Hullett, C. R. (2002). Eta squared, partial squared, and misreporting of effect size in communication research. Human Communication Research, 28, 612-625. https://doi.org/10. 1111/j.1468-2958.2002.tb00828.x.

Lopez-Navas, A., Rios, A., Riquelme, A., Martinez-Alarcon, L., Pons, J. A., Miras, M., .. Parrilla, P. (2011). Psychological care: Social and family support for patients awaiting a liver transplant. Transplantation Proceedings, 43(3), 701-704. https://doi.org/10.1016/j.transproceed.2011.01.095

Maldonado, J. R., Dubois, H. C., David, E. E., Sher, Y., Lolak, S., Dyal, J., \& Witten, D. (2012). The stanford integrated psychosocial assessment for transplantation (SIPAT): A new tool for the psychosocial evaluation of pre-transplant candidates. Psychosomatics, 53(2), 123-132. https://doi.org/10.1016/j.psym.2011.12.012

Malik, P., Kohl, C., Holzner, B., Kemmler, G., Graziadei, I., Vogel, W., \& Sperner-Unterweger, B. (2014). Distress in primary caregivers and patients listed for liver transplantation. Psychiatry Research, 215(1), 159-162. https://doi.org/10.1016/j.psychres.2013.08.046

Marteau, T. M., \& Bekker, H. (1992). The development of a six-item short-form of the state scale of the spielberger state-trait anxiety inventory (STAI). The British Journal of Clinical Psychology, 31(Pt 3), 301-306. https://doi.org/10.1111/j.2044-8260.1992.tb00997.x

Martin, S. C., Stone, A. M., Scott, A. M., \& Brashers, D. E. (2010). Medical, personal, and social forms of uncertainty across the transplantation trajectory. Qualitative Health Research, 20(2), 182-196. https://doi.org/10.1177/1049732309356284

Martin-Rodriguez, A., Perez-San-Gregorio, M. A., Dominguez-Cabello, E., Fernandez-Jimenez, E., \& Perez Bernal, J. (2012). Affective status in liver transplant recipients as a function of selfperception of general health. Transplantation Proceedings, 44(9), 2619-2621. https://doi.org/ 10.1016/j.transproceed.2012.09.052

Martins, P. D., Sankarankutty, A. K., Silva, O. C., \& Gorayeb, R. (2006). Psychological distress in patients listed for liver transplantation. Acta Cirurgica Brasileira, 21(Suppl. 1), 40-43. https:// doi.org/10.1590/S0102-86502006000700010

Miller, L. R., Paulson, D., Eshelman, A., Bugenski, M., Brown, K. A., Moonka, D., \& Abouljoud, M. (2013). Mental health affects the quality of life and recovery after liver transplantation. Liver Transplantation: Official Publication of the American Association for the Study of Liver Diseases and the International Liver Transplantation Society, 19(11), 1272-1278. https://doi. org/10.1002/lt.23728

Moran, A., Scott, A., \& Darbyshire, P. (2011). Waiting for a kidney transplant: Patients' experiences of haemodialysis therapy. Journal of Advanced Nursing, 67(3), 501-509. https://doi.org/10. 1111/j.1365-2648.2010.05460.x

Nagin, D. S., \& Odgers, C. L. (2010). Group-based trajectory modeling in clinical research. Annual Review of Clinical Psychology, 6, 109-138. https://doi.org/10.1146/annurev.clinpsy.121208. 131413

Napolitano, M. A., Babyak, M. A., Palmer, S., Tapson, V., Davis, R. D., \& Blumenthal, J. A. (2002). Effects of a telephone-based psychosocial intervention for patients awaiting lung transplantation. Chest, 122(4), 1176-1184. https://doi.org/10.1378/chest.122.4.1176

Ng, H. J., Tan, W. J., Mooppil, N., Newman, S., \& Griva, K. (2015). Prevalence and patterns of depression and anxiety in hemodialysis patients: A 12-month prospective study on incident and prevalent populations. British Journal of Health Psychology, 20(2), 374-395. https://doi.org/ 10.1111/bjhp.12106

Olbrisch, M. E., Benedict, S. M., Ashe, K., \& Levenson, J. L. (2002). Psychological assessment and care of organ transplant patients. Journal of Consulting and Clinical Psychology, 70(3), 771-783. https://doi.org//10.1037/0022-006X.70.3.771 
Pearlin, L. I., \& Schooler, C. (1978). The structure of coping. Journal of Health and Social Behavior, 19(1), 2-21.

Radloff, L. S. (1977). The CES-D scale: A self-report depression scale for research in the general population. Applied Psychological Measurement, 1, 385-401. https://doi.org/10.1177/ 014662167700100306

Reilly-Spong, M., Reibel, D., Pearson, T., Koppa, P., \& Gross, C. R. (2015). Telephone-adapted mindfulness-based stress reduction (tMBSR) for patients awaiting kidney transplantation: Trial design, rationale and feasibility. Contemporary Clinical Trials, 42, 169-184. https://doi.org/10. 1016/j.cct.2015.03.013

Rogal, S. S., Dew, M. A., Fontes, P., \& DiMartini, A. F. (2013). Early treatment of depressive symptoms and long-term survival after liver transplantation. American Journal of Transplantation: Official Journal of the American Society of Transplantation and the American Society of Transplant Surgeons, 13(4), 928-935. https://doi.org/10.1111/ajt.12164; 10.1111/ajt.12164

Rogal, S. S., Landsittel, D., Surman, O., Chung, R. T., \& Rutherford, A. (2011). Pretransplant depression, antidepressant use, and outcomes of orthotopic liver transplantation. Liver Transplantation: Official Publication of the American Association for the Study of Liver Diseases and the International Liver Transplantation Society, 17(3), 251-260. https://doi. org/10.1002/lt.22231

Rosenberger, E. M., Dew, M. A., DiMartini, A. F., DeVito Dabbs, A. J., \& Yusen, R. D. (2012). Psychosocial issues facing lung transplant candidates, recipients and family caregivers. Thoracic Surgery Clinics, 22(4), 517-529. https://doi.org/10.1016/j.thorsurg.2012.08.001

Russell, R. T., Feurer, I. D., Wisawatapnimit, P., Salomon, R. M., \& Pinson, C. W. (2008). The effects of physical quality of life, time, and gender on change in symptoms of anxiety and depression after liver transplantation. Journal of Gastrointestinal Surgery: Official Journal of the Society for Surgery of the Alimentary Tract, 12(1), 138-144. https://doi.org/10.1007/s11605-007-0382-x.

Sainz-Barriga, M., Baccarani, U., Scudeller, L., Risaliti, A., Toniutto, P. L., Costa, M. G., . . Bresadola, F. (2005). Quality-of-life assessment before and after liver transplantation. Transplantation Proceedings, 37(6), 2601-2604. https://doi.org/10.1016/j.transproceed.2005.06.045

Santos, G. R., Boin, I. F., Pereira, M. I., Bonato, T. C., Silva, R. C., Stucchi, R. S., \& da Silva, R. F. (2010). Anxiety levels observed in candidates for liver transplantation. Transplantation Proceedings, 42(2), 513-516. https://doi.org/10.1016/j.transproceed.2010.01.009

Schulz, T., Niesing, J., Homan van der Heide, J. J., Westerhuis, R., Ploeg, R., \& Ranchor, A. V. (2013). Perceived health after kidney transplantation: A cross-sectional comparison of long-term and short-term cohorts. Transplantation Proceedings, 45(5), 2184-2190. http://doi.org/10.1016/j. transproceed.2013.03.029.

Spielberger, C. D., Gorsuch, R. L., Lushene, R., Vagg, P. R., \& Jacobs, G. A. (1983). Manual for the state-trait anxiety inventory (self-evaluation questionnaire). Palo Alto, CA: Consulting psychologists press.

Stewart, K. E., Hart, R. P., Gibson, D. P., \& Fisher, R. A. (2014). Illness apprehension, depression, anxiety, and quality of life in liver transplant candidates: Implications for psychosocial interventions. Psychosomatics, 55(6), 650-658. https://doi.org/10.1016/j.psym.2013.10.002 [doi]

Toimamueang, U., Sirivongs, D., Limumnoilap, S., Paholpak, S., Phanphruk, W., \& Chunlertrith, D. (2003). Stress and coping strategies among renal transplant candidates in a Thai medical center. Transplantation Proceedings, 35(1), 292-293.

Van den Bos, G. A. M. (1995). The burden of chronic diseases in terms of disability, use of health care and healthy life expectancies. European Journal of Public Health, 5(1), 29-34. https://doi.org/ 10.1093/eurpub/5.1.29

van den Broek, K. C., Kupper, N., van der Voort, P. H., Alings, M., Denollet, J., \& Nyklíček, I. (2014). Trajectories of perceived emotional and physical distress in patients with an implantable cardioverter defibrillator. International Journal of Behavioral Medicine, 21(1), 149-159 https://doi.org/10.1007/s12529-012-9275-9

Van der Bij, A. K., De Weerd, S., Cikot, R. J. L. M., Steegers, E. A. P., \& Braspenning, J. C. (2003). Validation of the Dutch short form of the state scale of the Spielberger state-trait anxiety 
inventory: Considerations for usage in screening outcomes. Community Genetics, 6(2), 84-87. https://doi.org/10.1159/000073003

Van der Plas, S. M., Hansen, B. E., de Boer, J. B., Stijnen, T., Passchier, J., de Man, R. A., \& Schalm, W. A. (2004). The liver disease symptom index 2.0; validation of a disease-specific questionnaire. Quality of Life Research, 13(8), 1469-1481. https://doi.org/10.1023/B:QURE.0000040797. 17449.c0

Vermeulen, K. M., Bosma, O. H., van der Bij, W., Koeter, G. H., \& Ten Vergert, E. M. (2005). Stress, psychological distress, and coping in patients on the waiting list for lung transplantation: An exploratory study. Transplant International: Official Journal of the European Society for Organ Transplantation, 18(8), 954-959. https://doi.org/10.1111/j.1432-2277.2005.00169.x

Ye, C., Zhuang, Y., Zhang, Y., Lin, Y., Ji, J., \& Chen, H. (2013). Anxiety, depression, and associated factors among inpatients waiting for heart transplantation. Shanghai Archives of Psychiatry, 25(3), 165-173. https://doi.org/10.3969/j.issn.1002-0829.2013.03.006

Yohannes, A. M., Müllerová, H., Hanania, N. A., Lavoie, K., Tal-Singer, R., Vestbo, J., . . Wouters, E. F. M. (2016). Long-term course of depression trajectories in patients with COPD: A 3-year follow-up analysis of the evaluation of COPD longitudinally to identify predictive surrogate endpoints cohort. Chest, 149(4), 916-926. https://doi.org/10.1016/j.chest.2015.10.081

Zipfel, S., Lowe, B., Paschke, T., Immel, B., Lange, R., Zimmermann, R., .. Bergmann, G. (1998). Psychological distress in patients awaiting heart transplantation. Journal of Psychosomatic Research, 45(5), 465-470. https://doi.org/10.1016/S0022-3999(98)00010-5

Received 30 August 2016; revised version received 29 March 2017 